\title{
How the Focus on Food Literacy in Ontario's Food Charter Toolkits Detracts from Meaningful Food (In)Security Action
}

Philippa Spoel, Professor, School of Liberal Arts Laurentian University

Colleen Derkatch, Associate Professor, Department of English Ryerson University

\begin{abstract}
This article examines the uneasy relationship between the values of food security and food literacy in the context of Ontario's local food charter discourse. It extends prior rhetorical research on the competing values and incongruous community identities that food charters constitute by exploring the emerging genre of the food charter toolkit which is intended to help community members implement food charter visions. Situating our analysis within a critical review of recent work on food literacy and its association with food (in)security, we argue that toolkits articulate a superficial and ineffective approach to achieving the food charter goal of "food security for all" because they recommend mainly food literacy initiatives as the primary means for building food-secure communities. Addressed to a privileged audience of citizen-consumers who possess the socio-economic capacity to engage in the toolkits' recommended actions at both personal and community levels, this genre problematically excludes food-insecure community members as an agentic audience. Despite the ostensible social equity goal to ensure food security for all community members, the prevalence of a neoliberal-communitarian food literacy discourse in the food charter toolkits obscures the systemic-economic causes of, and possible solutions to, food insecurity.
\end{abstract}

Keywords: food charters; food literacy; food security; local food; social justice; neo-communitarianism; active citizenship

In public health and community food policy and practice, the values of food security and food literacy are widely promoted as uncontroversial goods that all food systems should be designed to achieve. However, although food security and food literacy are both laudable goals in the abstract, they may, in practice, be fraught with logical and ideological tensions that could instead potentially exacerbate food insecurity and undermine social justice goals of community stakeholders working to improve local food systems. In this article, we combine the qualitative research methodology of rhetorical criticism (Derkatch \& Spoel,2017; Spoel \& Derkatch,2016,2020) with theoretical insights from critical health and food research (Cairns et al., 2013; Cairns \& Johnston, 2015; Gore \& Kothari,2013; Mendly-Zambo \& Raphael, 2019; Parker, 2020; Rosol, 2012; Schrecker, 2016; van Houdt et al., 20 II) to examine the uneasy relationship between the values of food security and food literacy in the context of Ontario's local food charter discourse.

Food charters are vision statements that articulate a community's "values, principles, and priorities for a just and sustainable food system that will promote health and food security for all" (Jaquith, 20II, p. 6). Food charters are typically short (one to two pages), non-binding meta-policy documents that chart a vision for a region's food system (see Figure 1). There are currently at least 28 regional food charters in Ontario. Throughout the province, Public Health Units and professional dietitians have been closely involved in the creation of food charters along with other community stakeholders participating in local food policy councils and coalitions. 
All Ontario charters in some way identify food security as an essential goal of the regional food systems they envision (Jaquith, 201I), usually by explicitly or implicitly referencing the UN's 1996 definition: "when all people, at all times, have physical, social and economic access to sufficient, safe and nutritious food that meets their dietary needs and food preferences for an active and healthy life" (Food and Agriculture Organization, p. 2). Some charters also refer to the broader goal of



community food security, which in Hamm and Bellows' (2003) foundational definition means when "all community residents obtain a safe, culturally acceptable, nutritionally adequate diet through a sustainable food system that maximizes community self-reliance and social justice" (p. 37). Although community food security is wider in scope than the UN definition, both concepts share the ultimate goal of ensuring food security for "all community residents."

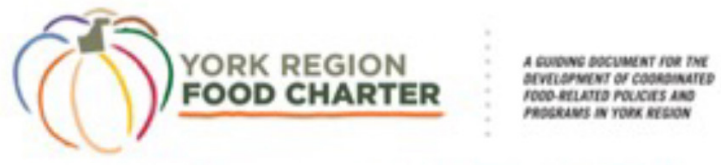

We believe a collaborative and integrated approach is essential to create a healthy and just food system for all.

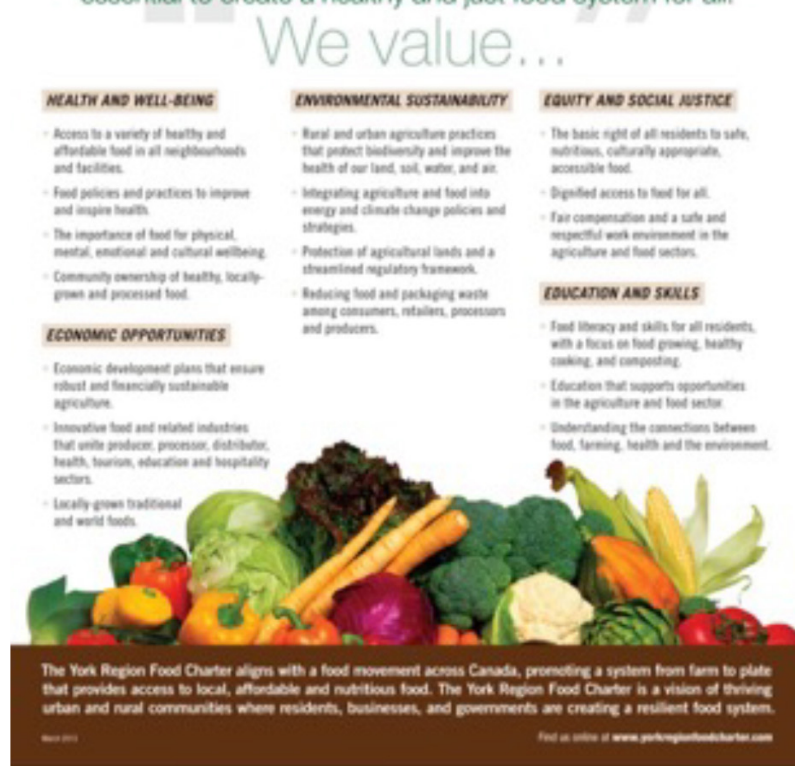

Figure I. Guelph-Wellington Food Charter (20II) and York Region Food Charter (20I3)

In previous research (Spoel \& Derkatch, 2016; Spoel \& Derkatch, 2020), we have shown that although food charters are helpful for conceptualizing progressive alternatives to global agri-business and industrial food systems, they also inadvertently constitute competing health values and incongruous community identities around local food that could hinder their capacity to increase public health and food security within the very communities they seek to benefit. Building on this prior scholarship, we focus here on the food charter toolkit, an emerging genre that six Ontario regions thus far have developed to help community members implement their food charter visions (see Table I).
Table I. Ontario Regions with Food Charter Toolkits

\begin{tabular}{|l|l|}
\hline Brant (20I9) & $\begin{array}{l}\text { https://feedbrant.ca/brant-food- } \\
\text { charter }\end{array}$ \\
\hline $\begin{array}{l}\text { Guelph-Wellington } \\
\text { (2013) }\end{array}$ & $\begin{array}{l}\text { https://povertytaskforce.files. } \\
\text { wordpress.com/20I3/II/gwfrt__ } \\
\text { toolkit_final_20I3.pdf }\end{array}$ \\
\hline $\begin{array}{l}\text { Leeds-Grenville- } \\
\text { Lanark (20I8-19) }\end{array}$ & $\begin{array}{l}\text { http://www.foodcorelgl.ca/_ } \\
\text { resources/Food_Charter_Eaters_ } \\
\text { Toolkit.pdf }\end{array}$ \\
\hline $\begin{array}{l}\text { Nipissing and Area } \\
\text { (20I5) }\end{array}$ & $\begin{array}{l}\text { https://nipissingareafood.ca/action- } \\
\text { toolkit/ }\end{array}$ \\
\hline $\begin{array}{l}\text { Parry Sound and } \\
\text { Area (n.d.) }\end{array}$ & $\begin{array}{l}\text { https://parrysoundareafood.com/ } \\
\text { action-toolkit }\end{array}$ \\
\hline York Region (2016) & $\begin{array}{l}\text { https://yrfn.ca/food-policy/york- } \\
\text { region-food-charter/toolkit/ }\end{array}$ \\
\hline
\end{tabular}


These toolkits are typically five to ten pages long, with separate sections addressed to different community sectors such as Eaters, Growers, Workplaces, Schools, and Policy Makers; each of these sections is further subdivided into lists of recommended actions each sector can take to support food charter principles. These principles typically include some version of Health, Education, Economy, Environment, Culture and Community, and Social Equity (see Figure 2)'. aimed at addressing "upstream determinants" of health inequities and the root causes of food insecurity (Gore \& Kothari, 2013, p. 52)².

We investigate these tensions by examining the kinds of actions that toolkits instruct "eaters" to take to help implement the food charter principles of Health, Education, and Social Equity. We focus on instructions to "eaters" because this is the audience category that

\section{Toolkit for Eaters}
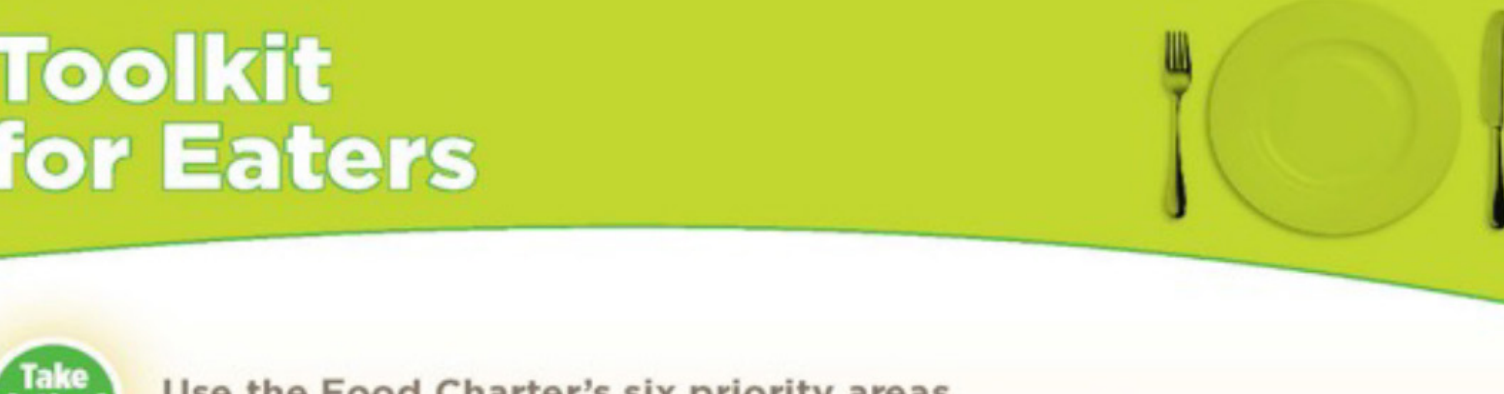

Use the Food Charter's six priority areas to see how you can make a difference.

Health
Take healthy cooking
classes"
Contact your local public
health unit for information
on healthy eating
Cook meals at home
When grocery shopping,
try to stick to the outside
perimeter, where there
are fewer processed foods

Education
Start a healthy snack
or lunch program at
your child's school or
your workplace
Teach children how to
cook healthy foods
Go to your local library
and take out some free
cookbooks on healthy
and seasconal cooking

\begin{tabular}{l}
\hline Sustainable \\
Economic \\
Development \\
When shopping, \\
choose local stores \\
and products when \\
possible \\
Join a local Community \\
Supported Agriculture \\
(CSA) initiative* \\
Visit your local \\
farmers' market
\end{tabular}

Environment
Learn to grow a few
of your favourite
vegetables and fruit
Support local farmers
and ecological food
production
Eat seasonally when
possible

\begin{tabular}{l|l|}
\hline Culture & Social Justice \\
\hline $\begin{array}{l}\text { Join or start a } \\
\text { community garden }\end{array}$ & $\begin{array}{l}\text { Buy fair trade when } \\
\text { possible }\end{array}$ \\
\hline $\begin{array}{l}\text { Eat dinner with your } \\
\text { family more frequently }\end{array}$ & $\begin{array}{l}\text { Learn about food issues } \\
\text { in Canada's North }\end{array}$ \\
\hline $\begin{array}{l}\text { Attend local food } \\
\text { festivals and events }\end{array}$ & $\begin{array}{l}\text { Learn more about rural } \\
\text { communities }\end{array}$ \\
\hline Attend a food swap"*. & $\begin{array}{l}\text { Advocate for healthy } \\
\text { food allowance } \\
\text { for those on social } \\
\text { assistance }\end{array}$ \\
\hline
\end{tabular}

Figure 2. Guelph-Wellington Toolkit for Eaters Showing Division of Actions by Charter Principles

Although toolkits are clearly well-intentioned, our analysis finds that they offer, at best, a superficial and ideologically problematic approach to achieving the food charter goal of "food security for all" because they focus mainly on food literacy initiatives that rely on personal skills such as information-seeking, healthy meal preparation, and participation in community gardens and cooking classes as the primary means for building healthy food-secure communities. This neoliberalized focus on personal food literacy actions undertaken by privileged citizen-consumers means that toolkits provide little meaningful guidance for social-food justice initiatives

I The Brant toolkit is an exception to this. Although the Brant charter articulates six guiding principles, the toolkit does not sub-divide its recommended actions according to them. Instead, it provides one overall list of recommended actions for each community sector.

encompasses "all community residents" (Hamm and Bellows, 2003) for whom the food charter goal of food security is intended and toward whom food literacy initiatives are most likely to be targeted. The prominence of food literacy rhetoric within these documents, especially in relation to the principles of Health and Education but also to an extent in support of Social Equity, implicitly and problematically presumes that augmenting community members' food knowledge and skills will also somehow augment "food security for all." Further, while the toolkits do list some actions intended to support all residents having access to affordable, sufficient, nutritious food (for example, through donating food from personal gardens, volunteering in a community garden, implementing school food programs, and advocating for better wages and social assistance), these actions are addressed to an audience

2 In 2017-18, more than 13\% of households in Ontario experienced food insecurity (Tarasuk \& Mitchell, 2020, p. 3). 
of "eaters" who are not themselves affected by food insecurity or the socio-economic inequities that cause food insecurity. Toolkits thus constitute community members not only as citizen-consumers who have the means and motivation to take personal responsibility for their own health through informed lifestyle choices, but also as civil society actors who have a sense of civic duty and the socio-economic capacity to support the broader community's health and welfare (Spoel \& Derkatch, 2016; Spoel \& Derkatch, 2020). At first glance, this neo-communitarian "active citizen" identity (Rosol, 2012) and the toolkits' proposed collective activities such as community gardening seem to counter an individualistic health promotion framework. However, neo-communitarianism does not oppose but instead expands neoliberal health imperatives by enacting a paradoxical form of citizen responsibilization for both community and individual well-being (van Houdt et al., 20II). As Rosol (2012) describes in her study of community volunteering in urban gardens, the strategy of involving civil society actors combines "the political rationalities of a neoliberal ethos of self-responsibilization of the individual and the neo-communitarian ideal of active citizenship and the promotion of community sense" (p. 25I).

In what follows, we briefly review recent discussions of food literacy, including its problematic positioning as an effective means to address food (in)security, and then analyse how the food charter toolkits for the most part articulate a reductive, food-literacy dominated set of actions to support the principles of health, education, and social equity. This analysis foregrounds the troubling irony that while food charters and their corresponding toolkits claim to be aimed at ensuring no one in the community is food-insecure, the community members addressed by these documents are those who are already food-secure; contrary to the social justice value of equitable participation, food-insecure citizens are excluded as an agentic audience, instead figuring indirectly as passive recipients of civic actions undertaken by the toolkits' primary audience of socioeconomically privileged and voluntarily 'food literate' community actors.

\section{Food Literacy and Food Security}

The concept of food literacy constitutes a relatively recent addition to the concept of health literacy (Palumbo, 2016). Whereas early definitions of food literacy focused primarily on the development of food knowledge, skills, and behaviours to improve personal or household health, increasingly the concept also encompasses understanding and acting in ways that support community-level food security and broader ecological health through sustainable, "alternative" food systems. According to Palumbo (2016), recent conceptualizations of food literacy encompass "the individual skills and abilities which are needed to properly use food in order to: achieve health enhancement, contribute in the development of a sustainable agriculture, and concur in the accomplishment of social equity outcomes" (p. 102). Vigden and Gallegos' (2014) frequently cited definition likewise indicates the expansive scope of food literacy within contemporary public health discourse:

Food literacy is the scaffolding that empowers individuals, households, communities or nations to protect diet quality through change and strengthen dietary resilience over time. It is composed of a collection of inter-related knowledge, skills and behaviours required to plan, manage, select, prepare and eat food to meet needs and determine intake. (p. 54)

Thomas et al. (2019) similarly propose a wide-ranging definition: "Food literacy includes interconnected attributes organized into the categories of food and nutrition knowledge; food skills; self-efficacy and confidence; food decisions; and ecologic (external) factors" (p. 570). On one level, the inclusion of "ecologic factors" in this definition signals a recognition of the "impact of environmental factors" such as "food environments" and "social determinants" on people's capacity to "develop and apply knowledge, skills, and behaviors that are essential to healthy eating" (p. 563); however, ambiguously, ecologic factors in this framework also refer to a person's individual understanding of "food systems" and the importance, as an ethical consumer, of making "sustainable food choices (e.g. buying foods that are produced locally)" (p. 566).

Explicitly associating food literacy with "alternative" agro-food movements, Sumner (2013) and Cullen et al. (2015) advocate for an understanding of food literacy as involving not only knowledge and skills relevant to one's personal (or household) health but to broader community and ecological health as well. In Sumner's view (2013), "To effect positive change in a globalizing world, food literacy must move beyond individualized prescriptions ... to become a concept that can analyze current foodscapes and model sustainable alternatives" (p. 84) while Cullen et al. (2015) propose a "framework 
that situates food literacy at the intersection of community food security and food skills"; this "integrated ecological paradigm" emphasizes the need to enhance "knowledge of food systems, including how we can work together to create a safe, equitable, and healthy food supply" (pp. |4|, |43).

In contrast to these celebratory views of food literacy as empowering citizens to improve both their own health and the health of the commons, Kimura (20ll) critiques its emphasis on individual actions and consumer choices as opposed to broader, collective change. She argues that far from fostering greater health and socioeconomic equity, the alignment of food literacy in agrifood movements with the socio-economically elite practices of "ethical eating" and "reflexive consumption" reinforces rather than dismantles existing economic and social hierarchies (p. 468). Consonant with neoliberalized modes of health promotion, the focus of food literacy on "individual training and provision of information for people to 'make a right choice"' makes individuals rather governments primarily responsible for food system reform (p. 479).

Particularly troubling is the view in some public health discourse that improving citizens' food literacy will, somehow, improve their food security. For example, Vigden and Gallegos (201I) assert that food literacy supports food security by "providing greater resilience and resistance to changing economic and social changes. It helps to protect diet quality" (p. 28). For Begley et al. (2019), the value of food literacy approaches to addressing food insecurity arises from its connection to the "utilization pillar" of the FAO's four pillars of food security (availability, access, utilization, and stability). While acknowledging that the promotion of food literacy can only be part of the solution to food insecurity, they nonetheless agree with Vigden and Gallegos (201I) that, "Focusing on improving food literacy self-efficacy and skills may help people develop resilience to and manage food insecurity better" (p. 14). Similarly, Desjardins and Azevedo (2013) claim that, for at-risk youth, improving "food skills and food literacy can build not only better diets, but a degree of resilience that can help tide young people over during the inevitable times of change and insecurity" (p. 50). These views coincide with the increasing focus of public health and charitable food agencies on food literacy programming, which includes both personal skills development and community food initiatives, as a strategy to alleviate food insecurity (Gallegos, 2016, p. 139).
The claim that food literacy can meaningfully address food insecurity problematically assumes that foodinsecure citizens lack food knowledge and skills yet possess the material capacity to "make "healthy lifestyle choices' in the face of the societal structures and processes that restrain such choices" (Mendly-Zambo \& Raphael, 2019, p. 6). Further, as Tarasuk and colleagues' research on food insecurity demonstrates, community food initiatives such as collective kitchens, community gardens, and Good Food Box programs do little to address food insecurity (eg., Dachner et al., 2010; Huisken \& Tarasuk, 2016; Kirkpatrick \& Tarasuk, 2009; Loopstra \& Tarasuk (2013); Tarasuk, 200I); as they argue, public health efforts would therefore be better redirected from these kinds of food literacy-oriented interventions to advocating for economic reforms to ensure low-income households have adequate resources for food (Kirkpatrick \& Tarasuk, 2009). Gallegos (2016) similarly emphasizes that, although well-meaning, community kitchens, gardens, and cooking workshops "fail to reach the intended target group, and are not a long-term solution to food insecurity" (p. 139). As Collins et al. (2014) and Mendly-Zambo and Raphael (2019) underscore, in addition to being largely ineffective food-based solutions to an income-based public health problem, these kinds of community-level food literacy initiatives obscure the systemic-structural causes of food insecurity and reduce pressure on government to address these "upstream determinants" of health (Gore \& Kothari, 2013, p. I).

This brief review of the uneasy relationship between food literacy and food security in public health and community food discourse provides the critical context for our analysis of the actions that food charter toolkits ask community members to undertake.

\section{Toolkit Analysis and Discussion}

To understand how toolkits both index and contribute to this uneasy relationship, we examine here the actions that they instruct "eaters" to perform in support of the typical food charter principles of Health, Education, and Social Equity (see Table 2 for the specific wording each toolkit uses for these principles). We selected these three principles because Health and Education suggest alignment with a "personal skills" approach to food literacy while Social Equity suggests, at least in name, some alignment with a social justice approach to food (in) security. 
Table 2. Phrases Used by Each Toolkit for the Principles of Health, Education, \& Social Equity

\begin{tabular}{|c|c|c|c|}
\hline Toolkit & Health principle & Education principle & Social Equity principle \\
\hline Brant & $\begin{array}{c}\text { Individual and Community Health and } \\
\text { Well-Being }\end{array}$ & Education and Skills & Fairness and Dignity for All \\
\hline Guelph-Wellington & Health & Education & Social Justice \\
\hline Leeds-Grenville-Lanark & $\begin{array}{l}\text { Everyone has enough healthy food to } \\
\text { eat. / Our communities are healthy, } \\
\text { economically diverse and resilient. }\end{array}$ & $\begin{array}{l}\text { Everyone has the food skills } \\
\text { and knowledge they need. }\end{array}$ & $\begin{array}{l}\text { Everyone has enough } \\
\text { healthy food to eat. }\end{array}$ \\
\hline Nipissing \& Area & Health \& Wellness & Food Literacy & Social Equity \\
\hline Parry Sound \& Area & $\begin{array}{l}\text { Residents' Health } \\
\text { \& Well-Being }\end{array}$ & $\begin{array}{l}\text { Foster Residents' Health } \\
\text { \& Well-Being }\end{array}$ & $\begin{array}{l}\text { Support Equal Access } \\
\text { Opportunities }\end{array}$ \\
\hline York Region & Health and Wellbeing & Health and Wellbeing & Social Justice and Equity \\
\hline
\end{tabular}

To conduct this analysis, we first compiled the actions listed by each toolkit for each principle. We then compared all the actions listed by all the toolkits for each principle, grouping them according to emergent themes as shown in Table 3. This coding provided a framework for understanding both the variety of actions called for across the three principles as well as their areas of overlap.

Table 3. Themes for the Principles of Health, Education, and Social Equity

\begin{tabular}{|c|c|}
\hline Toolkit principle & Themes (actions for eaters) \\
\hline Health & $\begin{array}{l}\text { I. Eat healthy food- } \\
\text { 2. Learn about healthy eating } \\
\text { 3. Volunteer in community-based food-related activities }\end{array}$ \\
\hline Education & $\begin{array}{l}\text { I. Learn about healthy eating } \\
\text { 2. Volunteer in community-based food-related activities } \\
\text { 3. Educate others }\end{array}$ \\
\hline Social Equity & $\begin{array}{l}\text { I. Learn about food justice / food insecurity } \\
\text { 2. Advocate for food access and income security } \\
\text { 3. Donate to food emergency programs } \\
\text { 4. Buy socially just food }\end{array}$ \\
\hline
\end{tabular}

\section{Actions for Health and Education}

As Table 2 indicates, we found considerable overlap in the types of action recommended under the principles of Health and Education, specifically those related to learning about healthy eating and to volunteering in community-based activities. Our analysis below therefore combines discussion of the actions listed within these overlapping themes. We discuss the first Health theme (Eat healthy food) and the third Education theme (Educate others) separately.

\section{Eat Healthy Food (Health Theme)}

The greatest portion of toolkit actions for eaters listed in support of Health focus on behaviours related to consuming healthy food. This includes the standard

3 Unlike the other toolkits, Leeds-Grenville-Lanark's does not have one single principle clearly focused on health; instead, attention to this value seems to be distributed across and mixed in with the two principles listed here. health-promotion instruction to eat "healthier" food, as seen in the advice to "Try new fruits and vegetables" (Guelph-Wellington, 2013) and "Incorporate more vegetables and fruit into meals and snacks" (Parry Sound, n.d.) as well as in directives to choose and purchase healthy foods and to prepare foods in ways that are healthier. For instance, eaters are advised to "Choose fresh foods more often" (York Region, 2016), to avoid shopping for "processed foods" (Guelph-Wellington, 2013), to "Cook meals at home" (Guelph-Wellington, 2013), to "Freeze or preserve fresh food" (Brant, 2019), and to "Practice making food from scratch and involve children in family food preparation" (FoodcoreLGL, 2019). Taken together, these instructions reinforce the neoliberal presumption that individual citizens have both the duty and the ability to engage in the recommended behaviours to support their own as well as their family's nutritional health and overall well-being. 
Although these instructions do not explicitly identify women as their presumed audience, they reinforce gendered and elitist norms of food-work by implicitly appealing to the ideal of the good mother who cares for her family's health through food (Cairns \& Johnston, 2015). As Cairns et al. (2013) have shown, increasingly this includes the expectation that the responsible mother will "preserve their children's purity and protect the environment through conscientious food purchases" (p. 97) as well as through participation in community gardens and other community food projects (Cairns \& Johnston, 2015). Meeting this ideal assumes and requires socio-economic privilege. The techniques of healthy and ethical food consumption that the toolkits articulate therefore clearly do not address community members who are food-insecure-citizens who may barely be able to afford any (let alone "new" or "more") fruits and vegetables or to "choose" fewer processed foods, and who may not have fully equipped kitchens or other resources needed to "cook meals at home" and "preserve fresh food."

\section{Learn about Healthy Eating (Health and Education Theme)}

Many of the actions listed in support of the principle of Health strongly resemble those identified under the principle of Education. This is especially true for actions associated with the theme "learn about healthy eating". Like the first Health theme, this theme also foregrounds the centrality of personal responsibility to live healthily; but consonant with the ideal of the informed-reflexive health citizen, it focuses especially on food-literacy actions aimed at improving eaters' knowledge and skills about food. For example, these sections exhort eaters to "Contact your local public health unit for information on healthy eating" (Guelph-Wellington, 2013), "Learn how to read nutrition labels" (York Region, 2016), ${ }^{4}$ "Take healthy cooking classes" (Guelph-Wellington, 2013), "Borrow library books on healthy, seasonal cooking and growing food" (Nipissing, 2015), "Enjoy Eat Right Ontario's recipe database" (York Region, 2016), or "Participate in training that focuses on nutrition, food safety, growing food and cooking" (Parry Sound, n.d.).

Some of the listed actions for this theme also reflect, in a superficial way, the expansion of food literacy to include matters of food sustainability and, especially, local agriculture. We see this in how the toolkits highlight the

4 Eat Right Ontario, recently rebranded as Unlock Food, is run by Dietitians of Canada. importance of becoming literate about seasonal food and local farming, for instance through advice to "Learn about foods that are in season" (FoodcoreLGL, 2019), "Find out what foods are grown near you" (Brant, 2019), and "Learn about community supported agriculture" (Brant, 2019); citizen-consumers are also encouraged to "Get to know your local farmers by shopping at farm gates or farmers' markets" (York Region, 2016).

In these ways, the toolkits' instructions configure eaters primarily as reflexive, conscientious citizenconsumers who have the resources of energy, finances, time, and transportation to go to the library, search online databases, take cooking classes, research local food availability, buy food from farm gates, and spend time getting to know local farmers. Parker (2020) notes how the expansion of individual responsibility for bodily health to responsibility for environmental health through discourses of ethical eating reinforces hegemonic femininities and norms of "good" citizenship (p. 44). In relation to the food charter goal of food security, these norms and their entailed actions seem troublingly inappropriate for addressing the distress of community members experiencing food insecurity which, as Schrecker (2016) underlines, "is a function not only of income poverty but of 'time poverty' and the exhaustion that goes with chronic precarity" (p. 2).

The significant overlap of Health and Education actions for the theme "Learn about healthy eating" suggests how the relationship between food and health is increasingly being addressed through the framework of food literacy. It also, we argue, positions the development of food literacy as more important than addressing the material conditions that make healthy eating inaccessible for far too many citizens.

\section{Volunteer in Community-based Food-related Activities (Health and Education Theme)}

The third theme reinforces the presumption of a socioeconomically privileged category of eaters and signals the significance in food charter discourse of a neocommunitarian "active citizenship" ideology (Rosol, 2012) that expands food-related health practices beyond personal responsibility for supporting one's own or one's family's well-being to responsibility for undertaking voluntary actions that (ostensibly) contribute to community health and well-being. This includes instructions to "Participate in or initiate a 'wellness committee' at your school, workplace or recreation club to define and implement healthy eating" 
(Nipissing, 2015), "Establish or volunteer in a community garden" (Parry Sound, n.d.), "Join or start a community kitchen program in your community" (Foodcore LGL, 2019), "support your local Good Food Box program" (Parry Sound, n.d.), and "volunteer with a community food or nutrition program" (Brant, 2019).

Each of these actions constitutes eaters as civil society actors who are both motivated and able to invest their time, knowledge, and goodwill voluntarily in communitylevel initiatives aimed at enhancing food literacy and food security mainly for other community members. As noted earlier, however, the effectiveness of interventions such as community gardens at addressing food insecurity is questionable (although they may have other communitylevel benefits). This configuration of eaters reinforces the downloading of state-level responsibility for collective health and welfare onto the unpaid labour of volunteers and the (scarce) resources of community-level, civil society enterprises. It also implicitly positions foodinsecure citizens as passive recipients of these enterprises rather than agentic participants in determining food policies and food security practices.

\section{Educate Others (Education Theme)}

The final theme associated with the principle of Education further expands the scope of food literacy and, accordingly, the kind of health citizen that toolkits promote. Rather than figuring eaters mainly as learners, it characterizes them as informal educators who can and should enhance their family and friends' food literacy. We see this in directives such as "Teach your family or friends how to grow or prepare food from scratch" (Brant, 2019), "Teach children how to cook healthy foods" (Guelph-Wellington, 2012), or "Check out cookbooks on healthy and seasonal eating at your local library" then "Share what you find with neighbours and friends" (FoodcoreLGL, 2019). These Education actions constitute the good health citizen not only as someone who takes initiative to become personally well-informed about healthy, seasonal, local food, but who also fulfills their duty, as an ethical parent and friend, to promote food literacy in others.

\section{Actions for Social Equity}

Combined, the toolkit instructions to eaters under the principles of Health and Education focus primarily on their individual responsibility to consume healthy local foods, become more food literate, and volunteer in community food initiatives; notably, these toolkit sections interpellate a relatively privileged health citizen rather than citizens experiencing food insecurity, and their recommended actions for the most part do not articulate meaningful ways to achieve greater food security for all community members.

But what about the actions that eaters are encouraged to take in support of the toolkits' Social Equity principle? How, if at all, do these sections promote more structuralsystemic approaches to addressing the socio-economic inequities that are the root cause of food insecurity? And how, if at all, are community members who experience food insecurity figured as actors and decision-makers in these sections, in ways consonant with the principles of social and environmental justice?

\section{Learn about Food Justice / Food Insecurity (Social Equity Theme)}

The short answer to the last question is that foodinsecure community members are not addressed as actors or decision-makers by these sections. The most common type of action that eaters are asked to engage in to support Social Equity in their communities is, once again, to become more literate, though in this case through developing their literacy about food insecurity rather than seasonal food and healthy meal preparation. Eaters are instructed, for instance, to "Learn more about issues that impact food security" (Nipissing, 20I5), "Learn about household food insecurity and effective solutions to fix it" (Brant 2019), "Learn from Food Secure Canada about the Right to Food" (York Region, 2016), "Learn about Indigenous food sovereignty" (Brant, 2019), and "Consider the role of income solutions to ... address ... poverty, which leads to food insecurity" (FoodcoreLGL, 2019). Although these recommendations may well represent a potentially valuable form of consciousnessraising for some community members, they are clearly addressed to those who do not have lived experience and embodied knowledge of food insecurity. Because learning about food insecurity is the most prominent type of action under Social Equity, the toolkit genre also distances eaters from politically-meaningful collective activism to address social and health inequities in their communities. Rather than countering the food literacy framework found in the Health and Education sections, this figuration of the eater-as-learner in the Social Equity sections expands the framework's scope. Community members are exhorted to become more informed about food (in)security as if simply becoming informed will somehow contribute directly to improving food security for all community members. 


\section{Advocate for Food Access and Income-Security (Social Equity Theme)}

A few of the other actions listed in these sections do encourage eaters to become more politically engaged by participating in advocacy work related to food access and income disparities. For example, two toolkits ask eaters to advocate for (not only learn about) systemicstructural issues such as "sufficient social assistance and disability benefits; affordable housing and transportation; and a living wage to ensure access to healthy food for all" (Parry Sound, n.d.) However, only one of these toolkits gives any direction on how to do so, and that is simply the generic directive to "Talk to your local politicians" (Nipissing, 2016, our emphasis). The lack of clear instruction for concrete steps eaters can and should take to ensure community food security underscores the genre's limited, superficial nature.

\section{Donate to Food Emergency Programs (Social Equity Theme)}

A third way in which the toolkits invite eaters to support the principle of Social Equity is through philanthropic contributions to local food programs. Community members are, for example, encouraged to "Support local food access programs financially or with donations of healthy foods" (FoodcoreLGL, 2019), donate "high quality, healthy food to food banks and food drives" (Nipissing, 2015), and provide home-grown produce to "a local food share program" (Parry Sound, n.d.). Though no doubt well-intentioned, these instructions reinforce the hierarchical positioning between eatercitizens who donate and food-insecure citizens who rely on such donations. They also reinscribe reliance on emergency food programs to address community food insecurity which conflicts with food charter visions for more socially just and sustainable food systems. Incongruously, the toolkits reaffirm, rather than critique, the need for civil society enterprises such as food banks to make up for reductions and chronic insufficiencies in state-supported health and welfare programs.

\section{Buy Socially Just Food (Social Equity Theme)}

Finally, four of the toolkits present ethical consumption as supporting Social Equity by exhorting eaters to "Buy" or "Use" fair trade products (Guelph-Wellington, 2012; Nipissing, 2015; Parry Sound, n.d.; FoodcoreLGL, 2019). While this form of consumerism may contribute in some small way to addressing global inequities, it is hard to see how it helps to address the health inequity of food insecurity within local communities in any substantive or direct way.

Ultimately, while a few of the actions listed under Social Equity for eaters do foreground the need for advocacy work on systemic, upstream determinants of health and food security, for the most part the actions listed are either politically superficial or they reaffirm ideologically problematic ways (such as emergency food programs and so-called ethical consumerism) of addressing health inequities and the root causes of food insecurity. From a social-food justice perspective, the toolkit sections on Social Equity are also very limited because they address community members primarily as individual food-secure residents engaged in personal-private actions rather than as a collective citizenry engaged in participatory decisionmaking and activism. The toolkits' recommended actions for social equity not only perpetuate a neoliberal/neocommunitarian ideology of personal responsibility for individual and community health; they also hierarchically separate the "haves" from the "have-nots." Rather than identifying participatory political actions that might join all community members in working together for greater collective social-health equity, the food charter toolkits split these community members apart.

\section{Conclusion}

The prevalence of food literacy discourse within not only the Health and Education but also the Social Equity sections of the food charter toolkits highlights their very limited political capacity to address systemic-structural determinants of food insecurity for community members. What is perhaps most troubling about the recommended actions in these toolkit sections is that they are clearly intended for citizen-consumers who already possess the socio-economic resources to engage in both personal and community-level food literacy enterprises. In this sense, the phrase "eaters" to name the community sector being addressed is ironically appropriate, as the citizens interpellated by the toolkits are precisely not those who lack "sufficient, safe and nutritious food that meets their dietary needs and food preferences for an active and healthy life" (Food and Agriculture Organization, 1996, p. 2). Despite Ontario food charters' commonly stated goal to ensure food security for all, our analysis shows how food charter toolkits fail to recommend meaningful political action for addressing the public health problem of food insecurity in Ontario communities. By focusing on individual citizen responsibilities and the development of personal 
knowledge and skills, the increasing prominence of food literacy discourse in this and other contexts obscures the systemic-structural causes of, and solutions to, health inequities.

Though clearly motivated by the desire to improve food security for all, food charters and their "toolkits" perhaps inevitably are not as logically coherent or ideologically unified as intended because they are complex discursive sites that attempt to bring together a wide range of competing interests and values (Spoel \& Derkatch, 2016). To the extent that public health and dietetics are involved in these initiatives with the goal of achieving food security for all, we would recommend greater discrimination concerning what aspects do and do not directly address this goal. In particular, we recommend taking care to distinguish between actions that promote individual citizens' food literacy via engagement in local food systems and actions that directly address the systemic problem of food insecurity. It may be that the food charter and toolkit genres are not the best venue for pursuing the agenda of ensuring food security for all residents, whereas engaging with organizations such as PROOF (Food Insecurity Policy Research) might be a more politically meaningful way for public health and the dietetic profession to help address the root causes of food insecurity.

\section{Author Bios}

Philippa Spoel is Professor of Rhetoric in the School of Liberal Arts at Laurentian University in Sudbury, Canada. Her research focuses on rhetorical criticism of health and environmental communication, including public health promotion, discourses of food security and food literacy, midwifery communication, lay perspectives on healthy living, and environmental controversies.

Colleen Derkatch is Associate Professor of Rhetoric in the Department of English at Ryerson University in Toronto, Canada. Her research focuses on rhetoric of health and medicine, particularly regarding the intersections between different understandings of and approaches to health and health care.

\section{References}

Begley, A., Paynter, E., Butcher, L. M., \& Dhaliwal, S. S. (2019). Examining the association between food literacy and food insecurity. Nutrients. II (2), e445. 10.3390/nul 1020445

Brant Food System Coalition (2019). Brant food charter toolkit. https://feedbrant.ca/brant-food-charter

Cairns, K., Johnston, J., \& MacKendrick, N. (2013).
Feeding the 'organic child': Mothering through ethical consumption. Journal of Consumer Culture, 13(2), 97-118. 10.1177/1469540513480162

Cairns, K., \& Johnston, J. (2015). Food and femininity. Bloomsbury.

Collins, P., Power, E. M., \& Little, M. H. (20l4). Municipal-level responses to household food insecurity in Canada: a call for critical, evaluative research. Canadian Journal of Public Health, 105(2), el38-4I. 10.17269/cjph.105.4224

Cullen, T., Hatch, J., Martin, W., Higgins, J. W., Sheppard, R. (2015). Food literacy: Definition and framework for action. Canadian Journal of Dietetic Practice and Research, 76(3) |40-|45. 10.3148/cjdpr-2015-010

Dachner, N., Ricciuto, L., Kirkpatrick, S. I, \& Tarasuk, V. (20I0). Food purchasing and food insecurity among low-income families in Toronto. Canadian Journal of Dietetic Practice and Research, 7I, e50-e56.

Derkatch, C.\&Spoel,P. (2017). Publichealth promotion of "local food": Constituting the self- governing citizen-consumer. Health 2I (2), I54-170. 10.1177\%2FI363459315590247

Desjardins, E. \& Azvedo, E., et al. (2013). "Making something out of nothing": Food literacy among youth, young pregnant women and young parents who are at risk for poor health. Public Health Ontario, Locally Driven Collaborative Projects (LDCP). http://www.osnpph.on.ca/resources/index. phphttp://foodsecurecanada.org/sites/default/files/ report_Idcp_foodskills_dec2013.final5_.pdf

Food and Agriculture Organization of the United Nations (1996). Rome declaration on world food security and world food summit plan of action. World Food Summit, November 13-17, 1996, Rome. http://www.fao.org/3/w3613e/ w3613e00.htm

FoodcoreLGL (2019). Eaters' Toolkit. http://www.foodcorelgl. ca/_resources/Food_Charter_Eaters_Toolkit.pdf

Gallegos, D. (2016). The nexus between food literacy, food security and disadvantage. In H. Vidgen (Ed.), Food literacy. Key concepts for health and education (pp. 134-150). Routledge.

Gore, D. M. \& Kothari, A. R. (2013). Getting to the root of the problem: health promotion strategies to address the social determinants of health. Canadian Journal of Public Health, 104(I), e52-e54. 10.1007/BF03405654

Guelph-Wellington Food Round Table (2013). Your GuelphWellington food charter toolkit. https://povertytaskforce. files.wordpress.com/2013/11/gwfrt_toolkit_final_2013.pdf

Hamm, M. W., \& Bellows, A. C. (2003). Community food security: Background and future directions. Journal of Nutrition and Education Behavior, 35(I), 37-43. 10.1016/ sl499-4046(06)60325-4

Huisken, A., Orr, S. K., \& Tarasuk, V. (2016). Adults' food skills and use of gardens are not associated with household food insecurity in Canada. Canadian Journal of Public Health, 107(6), e526-e532. 10.17269/cjph.107.5692

Jaquith, M. (201I). An assessment of Canadian food charters: 
Highlights and recommendations for the KFL\&A Healthy Eating Working Group. KFL\&A Public Health. http:// foodpolicykfla.ca/An_Assessment_of_Canadian_Food_ Charters.pdf

Kimura, A. H. (20ll). Food education as food literacy: Privatized and gendered food knowledge in contemporary Japan. Agriculture and Human Values, 28, 465-482. 10.1007/ SI0460-010-9286-6

Kirkpatrick, S. I. \& Tarasuk, V. (2009). Food insecurity and participation in community food programs among lowincome Toronto families. Canadian Journal of Public Health, 100(2), 135-139. 10.17269/cjph.100.1771

Loopstra, R. \& Tarasuk, V. (2013). Perspectives on community gardens, community kitchens and the Good Food Box program in a community-based sample of low-income families. Canadian Journal of Public Health, 104(I), e55-9. 10.1007/BF03405655

McLaughlin, C., Tarasuk, V., \& Kreiger, N. (2003). An examination of at-home food preparation activity among low-income, food insecure women. Journal of the American Dietetic Association, 103, 1506-1512. 10.1016/j. jada.2003.08.022

Mendly-Zambo, Z. \& Raphael, D. (2019). Competing discourses of household food insecurity in Canada. Social Policy and Society, 18(4), 535-554. 10.1017/S1474746418000428

Nipissing and Area Food Roundtable (2015). Nipissing and area food charter toolkit. https://nipissingareafood.ca/ action-toolkit/

Parry Sound \& Area Food Collaborative (n.d.). Toolkits. https://parrysoundareafood.com/action-toolkit/

Palumbo, R. (2016). Sustainability of well-being through literacy: The effects of food literacy on sustainability of well-being. Agriculture and Agricultural Science Procedia, 8, 99-106. 10.1016/j.aaspro.2016.02.013

Parker, B. (2020). Consuming health, negotiating risk, eating right: Exploring the limits of choice through a feminist intersectional lens. Journal of Critical Dietetics, 5(I), 45-57. 10.32920/cd.v5il.1336

Rosol, M. (2012). Community volunteering as neoliberal strategy? Green space production in Berlin. Antipode, 44(I), 239-257. 10.1111/j.1467-8330.2011.00861.x

Schrecker, T. (2016). 'Neoliberal epidemics' and public health: sometimes the world is less complicated than it appears. Critical Public Health, 26(5), 477-480. 10.1080/09581596.2016.1184229

Spoel, P. \& Derkatch, C. (2016). Constituting community through food charters: A rhetorical-genre analysis. Canadian Food Studies, 3(I), 46-70. 10.15353/cfs-rcea. v3il.144

Spoel, P. \& Derkatch, C. (2020). Resilience and self-reliance in Canadian food charter discourse. Poroi, 15(I), Article 8. 10.13008/2151-2957.1298

Sumner, Jennifer (2013). Food literacy and adult education:
Learning to read the world by eating. The Canadian Journal for the Study of Adult Education, 25(2), 79-92. https://cjsae. library.dal.ca/index.php/cjsae/article/view/1410

Tarasuk, V. (200I). A critical examination of communitybased responses to household food insecurity in Canada. Health Education \& Behavior, 28(4), 487-499. 10.1177/10901981010280040

Tarasuk, V. \& Mitchell, A. (2020) Household food insecurity in Canada, 2017-18. Toronto: Research to identify policy options to reduce food insecurity (PROOF). https:// proof. utoronto.ca/wp-content/ uploads/2020/03/HouseholdFoodlnsecurity-in-Canada-2017-20I8-FullReportpdf.pdf

Thomas, H., Azevedo Perry, E., Slack, J., Samra, H. R., Manowiec, E., Petermann, L., Manafo, E., \& Kirkpatrick, S. I. (2019). Complexities in conceptualizing and measuring food literacy. Journal of the Academy of Nutrition and Dietetics, 119(4), 563-573. 10.1016/j.jand.2018.10.015

van Houdt, F., Suvarierol, S., \& Schinkel, W. (201I). Neoliberal communitarian citizenship: Current trends towards 'earned citizenship' in the United Kingdom, France and the Netherlands. International Sociology, 26(3), 408-432. 10.1177/026858091039304|

Vidgen, H. \& Gallegos, D. (2014). Defining food literacy and its components. Appetite, 76, 50-59. 10.1016/j. appet.2014.01.010

Vigden, H. \& Gallegos, D. (201I). What is food literacy and does it influence what we eat: A study of Australian food experts. Queensland University of Technology, Brisbane.

York Region Food Network (2016). The York Region food charter toolkit. https://yrfn.ca/food-policy/york-regionfood-charter/toolkit/ 